First, Sven Reichardt reports that the "gender relationships and interactions in this alternative culture were more well-balanced than in any other contemporaneous youth culture" (p. 46). This is by no means an unimportant conclusion. Second, Reichardt points out, in the context of his discussion of the role of sexuality in this milieu, that it was precisely women who benefited the most from the less rigid standards prescribing sexual behaviour in the left alternative scene, certainly at the movement's highpoint in the late I970s and early i980s. And so it was with many other features described at great - sometimes excessive - length by Reichardt. Yes, there were countless hypocrisies and contradictions which marked this milieu like any other. But is this really so surprising? And, above all, did the negative features outweigh - or evenly balance with - the positive contributions made? I suggest not. Still, it is one of the great accomplishments of Sven Reichardt to provide ample evidence - or at least massive hints at - alternative ways of interpreting the accomplishments and contradictions of the environments under review.

One final comment: for a tome of this size to have a mere 18 -page conclusion is a major disappointment. Moreover, Io pages of this meagre conclusion are a mere summary of the preceding 870 pages. The actual 7-page "substantive" conclusion mostly repeats Reichardt's thesis, assessed by this reviewer in the preceding paragraphs. The conclusion does include one additional observation by Reichardt, the author's firm belief that, "in the last analysis", the "history of the left alternative milieu" forms an integral part of the longer story of the emergence of the "post-modern self" (p. 888). "They were on the one hand critics of the pluralist media society and culture of consumption - but they formed just as much a part thereof" (p. 890). Yes, indeed. Of course. How could it have been any different? As a conclusion to a path-breaking work of empirical scholarship, such a final assessment is decidedly underwhelming.

\title{
Gerd-Rainer Horn
}

Département d'Histoire, Institut d'Etudes Politiques de Paris (Sciences Po) 27 rue Saint Guillaume, 75337 Paris CEDEX 07, France E-mail: gerdrainer.horn@sciencespo.fr

Harvey, Kyle. American Anti-Nuclear Activism, 1975-I990. The Challenge of Peace. [Palgrave Studies in the History of Social Movements.] Palgrave Macmillan, Basingstoke 20I4. xii, 22 I pp. Ill. £60.00; € 91.95. doi:10.1017/ So020859015000619

The late I970s and the I980s constituted a time of worldwide public protest against nuclear weapons. Appalled by the revival of the nuclear arms race and loose talk by government officials about nuclear war, people around the world staged a major revolt. Western Europe was convulsed by massive anti-nuclear demonstrations, as was North America, Asia, and the Pacific region. Protest, although on a much smaller scale, also broke out in Latin America, Africa, the Middle East, and even in Soviet-dominated eastern Europe. With polls showing large majorities of the public in most nations supporting the protest campaigns, political parties and politicians fell into line. Public policymakers tempered their nuclear ambitions and turned, instead, to fostering nuclear arms control and disarmament while avoiding further talk of nuclear war. 
Although, at the time, journalists, activists, and scholars scrambled to provide hastily-written analyses of this surge of anti-nuclear activism, only in later years - when popular rebellion had faded and organizational records had become available - did scholars begin to mine the archives and conduct the interviews enabling them to put together comprehensive studies covering the anti-nuclear rebellion and the governmental response of the era. These studies include: David S. Meyer's A Winter of Discontent (Westport, CT, I990); David Cortright's Peace Works (Boulder, CO, I993); Jeffrey W. Knopf's Domestic Society and International Cooperation (Cambridge, I998); Matthew Evangelista's Unarmed Forces (Ithaca, NY, I999); Robert English's Russia and the Idea of the West (New York, 2000); Steve Breyman's Why Movements Matter (Albany, NY, 200I); and Lawrence S. Wittner's Toward Nuclear Abolition (Stanford, CA, 2003). Kyle Harvey's American Anti-Nuclear Activism, 1975-1990 (New York, 20I4) is the latest addition to this scholarly literature.

In this book, Harvey, who is based at Macquarie University in Sydney, Australia, examines the anti-nuclear movement in the United States, where it was indeed a major force during the first half of the I980s. In June 1982, nearly I million Americans turned out for a New York City rally against the nuclear arms race, the largest demonstration up to that point in US history. Meanwhile, the Nuclear Weapons Freeze Campaign - calling for a US-Soviet agreement to halt the testing, production, and deployment of nuclear weapons - drew the backing of most peace organizations, large labor unions, and mainstream religious bodies. Despite substantial attempts by the very hawkish administration of Ronald Reagan to discredit the Freeze movement, opinion pollsters reported that the Freeze had the support of 70 to 80 per cent of the general public. In the fall of 1982 , when activists placed the Freeze on the ballot, voters approved it in nine out of ten states where it appeared, including the President's home state of California. Boxed in by popular pressure, Reagan made a remarkable reversal in administration policy, scrapping his nuclear weapons buildup and pressing for nuclear disarmament.

Harvey, however, is much less interested in the movement's strength and efficacy than in its internal dynamics and diversity of approaches. Indeed, in a series of six case studies, he focuses primarily on points of tension within the movement, serious divisions that prevented it from acting in a unified fashion.

As the anti-nuclear movement gathered strength in the late i970s and early i980s, he argues, America's pacifist groups adopted a radical approach, attempting to forge a broad peace movement dedicated to "comprehensive social change". Thus, they clashed with other activists, who aimed "to develop a movement that would be more mainstream, mediafriendly, and moderate". This tension became particularly acute within Mobilization for Survival, a coalition venture, and in the planning for the massive June 1982 demonstration against the nuclear arms race. The Freeze, he notes, triggered the disdain of many pacifists and radicals, who viewed it as shallow and much too tactically cautious. In turn, Freeze activists, as he shows, tried hard to adhere to a mainstream approach that would appeal to most Americans.

When he outlines these tensions, Harvey is quite convincing. But he is somewhat less so when he describes the Freeze campaign and its moderate allies, the National Committee for a Sane Nuclear Policy (better known as SANE) and Women's Action for Nuclear Disarmament, as driven by a "corporate approach" when they sought to improve their fundraising, membership, and media impact. Important leaders within these organizations - such as Randy Forsberg, Randy Kehler, David Cortright, Helen Caldicott, and William Sloane Coffin, Jr - championed a less "conservative” approach than 
he implies, although they did, indeed, use every opportunity to develop a broadly-based movement to alter public policy.

Harvey also emphasizes the sharp division between moderate women's peace groups (focused on nuclear disarmament) and radical women's groups (focused on "separatism, a rejection of the patriarchy, and the expression of countercultural ideas about ecology and mysticism"). This conflict was played out at the Women's Peace Encampment at Seneca Falls, where, he shows, the dominance and lifestyle of radical feminists alienated women in this rural New York community and even women participants in the encampment.

Yet another component of the American anti-nuclear movement that Harvey examines is the Fast for Life - a venture designed to halt the nuclear arms race through a communal, open-ended fast. Supporters argued that such a fast would provide a better example of heroic self-sacrifice than the Freeze campaign did and, thus, millions of people around would be inspired to activism against nuclear weapons. Uneasy about the plan, the broader anti-nuclear campaign rejected it. Nevertheless, a small number of enthusiasts, undiscouraged, went ahead with their plan. The upshot was that the fast petered out after forty-one days, having received little or no attention from the mass media or the public.

One of the more interesting of Harvey's case studies focuses on activism in Lawrence, Kansas, a university town that provided the locale for the widely-viewed anti-nuclear film, The Day After (1983). The nuclear disarmament movement arose in Lawrence, as in other parts of the country, before anyone knew of the film. But, as Harvey demonstrates, the film widened and deepened the movement in Lawrence. The Day After also reinforced certain key themes in the local movement, particularly the role of "ordinary", supposedly typical Americans and the importance of local action. Ironically, Lawrence, as a liberal university town, was far from a typical rural community in the "American Heartland", an erroneous image portrayed in the film. Also, the question of what political issues were appropriate subjects of local concern was sharply contested within Lawrence, with some residents resisting the notion that their community should be dealing with the apparently distant issue of nuclear disarmament.

Finally, Harvey reveals how a diversity of approaches emerged in what was billed as the Great Peace March of 1986. Devised by businessman and political campaign strategist David Mixner, the March was supposed to be a "portable city" of 5,000 Americans hiking 3,700 miles from Los Angeles, California to Washington DC to take the message of nuclear disarmament directly to the American people. Harvey notes that, although the March began as "a glitzy, publicity-driven, mainstream affair", it soon evolved into "a grassroots endeavor that displayed a very different character". As funding, interest, and participation quickly fell away, radical, countercultural, and individualist emphases came to the fore, creating an "often troubled and uncomfortable relationship that social activism on the left had with the public it so desperately hoped to reach".

Overall, then, American Anti-Nuclear Activism makes the point that, as Harvey writes, the American anti-nuclear campaign of these years illustrates "the contested nature of activism". Readers of the book might well come away with the impression - as does this reader - that this fractiousness within the movement was debilitating. At least, they might conclude that some approaches championed by activists were quite unproductive. But Harvey takes a more benign view of conflict within the nuclear disarmament campaign, concluding mildly that "the story of anti-nuclear activism in the United States was one characterized by experimentation, compromise, and difference”. 
Thus far, scholarly studies of the anti-nuclear movement have focused on its moderate, mainstream forces and their interaction with public policy. Therefore, Harvey's emphasis on debate and organizational dynamics within the broader nuclear disarmament campaign fills a gap in the scholarly literature.

To make his case, Harvey draws upon numerous relevant manuscript collections, personal interviews with key activists of the era, periodicals, and published sources. He also employs a carefully-reasoned analysis, as well as a sophisticated writing style. Consequently, American Anti-Nuclear Activism, 1975-1990 emerges as a well-crafted, well-researched, and credible scholarly work. In summary, this book is an important contribution to existing scholarship on peace and disarmament movements and, more generally, to the scholarship on social movements.

Lawrence S. Wittner

Professor of History Emeritus State University of New York at Albany

Albany, NY I 2222, USA

E-mail: lwittner@albany.edu

Zhang, Lu. Inside China's Automobile Factories. The Politics of Labor and Worker Resistance. Cambridge University Press, New York [etc.] 201 5. xvi, 240 pp. Ill. \$95.00; £60.00; RMB 537.50. doi:10.1017/S00208 5901 5000620

In view of its rapid capitalist transformation, China's labour and industrial relations have attracted increased attention from scholars in recent years. In the growing body of literature on this topic, Lu Zhang's book is, to my knowledge, the first comprehensive study of labour relations in the Chinese automotive industry. As this industry is generally understood to be a forerunner in the development of labour relations, has been labelled "strategic" by the Chinese state, and has become a hotbed of worker activism, her work makes for a timely and highly relevant contribution to the field.

Zhang's stated aim is to understand the conditions, subjectivity, and collective actions of workers in China's car assembly industry. The core of her research consists of more than 300 interviews, as well as documents and observations, gathered from extensive fieldwork in the assembly plants of state-owned enterprises and Sino-foreign joint ventures over a seven-year period, 2004-20II. Zhang analyses her observations against the background of the structural transformation of China's automotive industry, seeking to explain the relationship of structure and subjectivity in working-class formation in China.

Framed by an introduction and a conclusion, Zhang's argument proceeds in six chapters, starting with an analysis of the most general structural conditions and transformations of the Chinese automotive industry, proceeding to the labour market and the social composition of the work force, the organization of production and the social order within factories, and finally to the concrete subjectivity, motivations, and actions of formally employed workers on the one hand and temporary workers on the other. Additionally, Zhang discusses the strategies of the state in dealing with an increasingly restive working class.

A recurring theme and point of reference throughout Zhang's analysis is how the capitalist development of the automotive industry has fostered conditions that at the same 